\title{
Diplomacy in Action: Latourian Politics and the Intergovernmental Panel on Climate Change
}

\author{
Matthijs Kouw \\ Rathenau Instituut, Netherlands / matthijs@matthijskouw.nl \\ Arthur Petersen \\ Department of Science, Technology, Engineering and Public Policy, University College London, United \\ Kingdom
}

\begin{abstract}
The Intergovernmental Panel on Climate Change (IPCC) reviews scientific literature on climate change in an attempt to make scientific knowledge about climate change accessible to a wide audience that includes policymakers. Documents produced by the IPCC are subject to negotiations in plenary sessions, which can be frustrating for the scientists and government delegations involved, who all have stakes in getting their respective interests met. This paper draws on the work of Bruno Latour in order to formulate a so-called 'diplomatic' approach to knowledge assessment in global climate governance. Drawing on observations during IPCC plenaries, this paper argues that a Latourian form of diplomacy can lead to more inclusive negotiations in climate governance. Latour's ideas on diplomacy help to identify values of parties involved with the IPCC plenaries, and allow those parties to recognize their mutual interests and perspectives on climate change.
\end{abstract}

Keywords: Diplomacy, IPCC, climate governance

\section{Introduction: the Intergovernmental Panel on Climate Change as a diplomatic arena}

It is obvious, or at least it should be, that the governance of climate change requires knowledge on what this global problem is all about, and where solutions may be found - it is not enough to conclude, following Bruno Latour, that we have arrived in the Anthropocene and that "Gaia is against us" (Latour, 2013: 486). Things become less obvious, however, when one tries to imagine the best way of connecting science and politics around questions concerning nature, which is something Latour (2004) addresses. Nature is commonly seen as a unifying element outside of the human sphere. However, Latour (2004) argues nature is not so much a unifying figure, but rather a dividing figure: pluralism is concomitant with 'nature', since society contains a multitude of often incommensurable perspectives on nature. 
In this paper, we examine how science and politics become intertwined in the plenary sessions of the Intergovernmental Panel on Climate Change (IPCC). The IPCC is an international body for the assessment of climate change that was established in 1988 by the United Nations Environment Programme (UNEP) and the World Meteorological Organization (WMO). The IPCC produces extensive analyses of scientific ${ }^{1}$ research on climate change in 7-year cycles that culminate in the production of Assessment Reports. These documents are finalized during plenary sessions in which all countries that are member of the United Nations or WMO can ensure their interests are met, which involves elaborate diplomatic procedures. The plenary sessions are led by an elected officer (in most cases the 'Working Group Co-Chair') who, besides having been nominated by his or her own country and having gained sufficient political support in larger groups of countries to get elected, is typically also one of the leading climate scientists in the world. ${ }^{2}$

One of the most important procedural rules during IPCC plenaries is that delegations need to reach consensus in the form of a univocally accepted report, which includes line-by-line approval of the so-called Summary for Policymakers (SPM). This way of organizing the proceedings slows things down quite a bit (it may take days to agree on just a couple of pages), but also offers opportunities for real diplomatic encounters between the authors and the representatives of countries. Not only do all of the countries present have to agree; the authors themselves also need to unanimously accept the SPM. The final accepted report, which includes the SPM, serves as the benchmark for the assessment of climate-related risks and measures for years to come, so the stakes are high indeed. The scientific reputation of the co-chairs and authors are on the line (since any overstatements on the reliability of the science or any underestimation of the risk of climate change may backfire later). At the same time, co-chairs and authors need to be flexible enough to deliver a report that is found useable by policymakers and politicians. The latter groups of actors (both bureaucrats and even ministers in some occasions) will consider the political 'spin' they can give to the report in the media in their countries, and what positions can be supported in the context of the UN Framework Convention on Climate Change (UNFCCC). Moreover, both groups - the scientists and the country delegates - are heterogeneous. Among the authors there are disagreements on what are the best representations of the scientific evidence, and among the countries there are clear and plain political divergences, which are mostly related to assessments of economic impacts of either climate change or of proposed solutions to climate change, or both. Even though the meetings of IPCC plenary sessions are closed to the public and journalists are not allowed in the room, there are organizations that keep a close eye on what is happening. These organizations include fossil fuel organizations, environmental NGOs, and other organizations that represent different interests.

The negotiations that ensue due to the partial compatibility of perspectives and interests can be likened to a prisoners' dilemma game, where countries are better off reducing their emissions collectively, but think they benefit more from continuing to emit individually. The plenary sessions of the IPCC involve a highly multiplicitous arena of voices, which somehow need to address climate change in unison and assess possible actions. As a result, plenary sessions involve an intense process of negotiation between numerous government representatives and the authors of IPCC reports. These negotiations involve organizational, legal, political, ethical and also psychological elements, besides debate on preferred scientific presentations of the evidence base. Often, the interests of the delegations involved only partially overlap. Not all country delegations are similarly composed; some countries give the lead of the delegation to their nation's meteorological office, and thereby attempt to prevent that political motives become visible in how they proceed. Ultimately, delegations operate according to a governmental instruction and as a result cannot escape from being involved with politics.

The plenary sessions leading to the acceptance of IPCC Assessment Reports have the potential to create an inclusive space for negotiation by allowing those involved to voice their opinion. However, the selection of representatives features 
exclusivity. Governments send representatives in the form of delegates who are involved with politics in their home countries. In the case of the climate system and possible 'solutions' to the problem of climate change, the IPCC's leadership selects representatives of scientific communities in the form of lead authors who reference scientific publications in their respective assessment chapters.

Science (through the authors) can play an important role as an epistemological arbiter in deciding what findings are seen as legitimate (i.e. supported by the underlying scientific literature). Although science is the dominant way of speaking that is deployed during IPCC proceedings, authors who believe in 'speaking truth to power' by means of 'objective' scientific insights are often surprised by the other ways in which delegates speak back, employing other registers of 'objectivity'. In turn, delegations who think they can speak power to science can find themselves overruled by scientific consensus. Ultimately, both sides have to respect each other and need to reach consensus.

In this article, we relate IPCC plenaries, seen as settings that are replete with all kinds of relations (e.g., political groups, legal means, organizational frames, emotional attachments) and different perspectives on climate change, with Latour's $(2002,2011,2013)$ work on Modernity and diplomacy, in particular his views on politics. Latour (1993) is renowned for arguing for the existence of 'imbroglios of humans and nonhumans' that defy comfortable categorization in modernist categories such as 'Nature' and 'Culture'. One need only open the newspaper, Latour (1993: $1 \mathrm{ff}$.) argues, to realize that science, politics, nature, and religion are often intertwined in such a way that clear-cut categories are of little help in understanding the world. Yet, during IPCC plenaries (and socio-technical controversies more generally) it is often Science that is mobilized as a universal arbiter that delivers exhaustive descriptions of issues and resolves misunderstandings. Latour refuses to take recourse to "Nature, as known by Reason" (Latour, 2002: 9) to resolve political conflicts. Instead, Latour (2004) argues that Nature, as explained by the natural sciences, has been mobilized as a disinterested third party, in the (vain) hope that it could settle questions related to environmental governance once and for all.

Latourian politics involves "the progressive composition of the common world" (Latour, 2002: 7). This common world cannot be taken for granted because it is not already constituted, and existing constructions may be challenged by alternative constructions. Diplomats play a prominent role in Latourian politics since they "know that there exists no superior referee, no arbiter able to declare that the other party is simply irrational and should be disciplined." (Latour, 2002: 37-38) Latour's idea of politics as progressive composition of the common world does not bode well for an approach to climate governance that relies primarily on science. After all, Latour (2002, 37-38) disagrees with the idea that objective scientific knowledge forms a universally valid arbiter that can resolve political conflicts once and for all. Thus, as we argue at greater length in section 3 , Latour's understanding of politics can be framed as a diplomatic project through and through, for it is diplomats who become the arbiters in the pluralistic political landscape he describes.

By intertwining Latour's work on politics and diplomacy with our experiences as members of the Dutch delegation during several IPCC plenaries (for AP this entails 7 plenaries in the period from 2001 until 2014; for MK two plenaries in 2014), we propose ways in which climate governance can be enriched. We argue that it is important to respect the diversity of political interests without losing appreciation of climate science. Doing so can help to ensure that the IPCC reports contribute in a meaningful manner to climate governance. We have observed both naivety and frustration among many authors about the political dimension of their IPCC work - and some have made pleas for getting rid of country-approved SPMs for that reason. In the end, however, some authors who were first new to the process become aware that they are themselves doing politics, rallying groups of countries behind their representation of the evidence base. We acknowledge that balancing science and politics can be a frustrating endeavor. Both delegations and authors may not want to find their perspectives ignored, but the inclusion of as many different perspectives as possible yields challenges as well. The process 
of ensuring the diverging interests of delegations and authors are met involves the hammering out of a document - where the actors are all operating under a multitude of organizational scripts - that can be accepted by all parties involved. In building this consensus, sacrifices may very well need to be made, which may also mean that the final texts become a collection of generic statements that are vague enough to allow different interpretations. Unanimous approval of the IPCC summaries is advantageous, since it forges documents with which all governments can in principle agree, also for use in subsequent negotiations within the UN climate convention (UNFCCC). The other side of the coin is that the documents produced become rather generic and unsuitable for the practice of climate governance. Highly sensitive issues can become veiled due to opaque language. Texts become inclusive of multiple opinions to the extent that they cover such a wide range of views on climate change that they lose specificity and, as a result, applicability in the domain of climate governance. A possible outcome is that policymakers are unable to use IPCC reports in any meaningful way.

Despite the presence of a multitude of voices, we do not believe that the IPCC has fully realized its diplomatic potential in terms of bridging the interests concomitant with heterogeneous perspectives. The IPCC can be better equipped to do justice to this multitude of voices, provided diplomatic interventions along the lines that Latour proposes are integrated more reflexively in the process of producing and approving IPCC reports. In order to illustrate the present difficulty of such diplomatic interventions (and the dominance of the order of speech that many authors would prefer to maintain), we draw on our experiences during IPCC plenaries to reflect on the inner workings of the IPCC. This analysis and the associated plea may help to improve future diplomatic encounters between science and politics in the activities of the IPCC.

Building an inclusive space of negotiation through diplomatic interventions aligns well with Bruno Latour's (2013) notion of diplomacy developed in his latest book An Inquiry into Modes of Existence (AIME), in which Latour focuses on 'diplomatic work' across various 'modes of existence'. Although this concept needs to be explained at greater length below, modes of existence can be provisionally defined as "different modes of being" that "emerge historically and internally to specific cultures, rather than being a priori categories of the mind or the world." (Bryant et al., 2011: 14) Each mode of existence has its own criteria for truth and is incommensurable with other modes. Table 1 below briefly illustrates the modes we deploy in our examination of the IPCC in this paper. Each mode is explained briefly in the table and will be explained in greater detail as our analysis proceeds. It should be noted that Latour's (2013) AIME describes a total of 15 modes. We cannot do justice to the depth of Latour's analysis and instead focused on those modes that in our view figured most prominently during the IPCC plenaries we attended. We adopt Latour's notation of the various modes, which consist of a three letter acronym between square brackets for each mode ${ }^{3}$.

Diplomacy can be performed by reflexively doing 'intermodal' work that untangles confused ontologies and facilitates understanding between the adherents of various modes of existence (Maniglier, 2014). This intermodal work invites those who subscribe to a particular mode of

Table 1. Latourian modes used in this paper.

\begin{tabular}{|l|l|}
\hline Mode & Description \\
\hline [POL] & $\begin{array}{l}\text { Politics, understood as an ongoing circular movement between attempts to achieve political } \\
\text { representation and attempts to unsettle existing political representations. }\end{array}$ \\
\hline [REF] & Reference. Latour uses this mode to refer to scientific representations. \\
\hline [ORG] & Organization, seen as the production and following of scripts. \\
\hline [ATT] & Attachment, a term Latour uses to refer to desires. \\
\hline [MOR] & Morality, understood as asking the question whether ends justify means. \\
\hline [LAW] & Law, understood as legal procedural connections between one step and the next. \\
\hline
\end{tabular}


existence (e.g. [POL] or [REF]) to redescribe themselves in the light of alterity, which can establish and improve intermodal communication. We deliver a somewhat instrumental reading of Latour's notion of diplomacy by arguing it can help to furnish the IPCC plenaries as a more inclusive political platform for climate governance. Our aim is not so much to use Latour's notion of diplomacy to solve the issue of climate change per se, but rather for cherishing institutionalized communication between science and politics, which can jointly characterize the problem of climate change. Our guiding question in this article is as follows: how can Latour's work on diplomacy enhance the IPCC plenaries as inclusive platforms for climate governance?

\section{Methodology and paper overview}

As stated above, we draw on our experiences as members of the delegation of the Dutch government during several IPCC plenaries. During these plenary sessions, we were part of a team responsible for ensuring the interests of the Netherlands were met during the negotiations. In this paper, we draw on our experiences during the IPCC plenaries that took place in Stockholm (September 23 to September 26 in 2013), Yokohama (March 25 to March 29 in 2014), and Copenhagen (October 27 to October 31 in 2014). Our methodology can be identified as the ethnographic approach of participant observation. On a daily basis we produced a combined reflexive log of the proceedings during the plenary sessions and contact groups and of our own roles in these. These logs were shared with governmental colleagues in the Netherlands. Our role was far from passive, since we were an active part of the negotiations that led to the approval and acceptance of IPCC reports. We proceeded as follows. First, we ensured that problems with the draft text of the IPCC report that were flagged by a team of specialists in the Netherlands were addressed during the IPCC plenaries. Second, close collaboration with others in the Dutch government led to sets of instructions tailored to each plenary session that needed to be followed through. As a result, the instructions acted as a script by shaping how we conducted ourselves in the mode of organization [ORG]. Awareness of the Dutch political context also went into these scripts $[\mathbf{P O L}]^{4}$. Third, we ensured collaborations and interventions were planned and executed when necessary.

Although we were very much part of the processes of negotiation between incompatible perspectives we describe in the following, we do not think this implies an insurmountable bias in our view of the IPCC. Rather, by articulating our own approach to these negotiations, we demystify our own preoccupations and actions in an attempt to make them transparent to the reader. Thus, our writing can be framed as an attempt to demonstrate the diplomatic interventions Latour (2013) discusses, which involve a process of allowing adherents of modes of existence (including, but not limited to scientific practitioners and policymakers ranging from bureaucrats and professional diplomats to ministers) to express themselves in their own terms, whilst respecting other modes and ensuring that negotiation among the different modes is enabled and fostered.

In relating Latour's work on diplomacy with the practices of the IPCC, we proceed as follows. The following section briefly illustrates concepts from Latour's (2013) work related to politics and diplomacy, and subsequently refines the notion of diplomacy as further developed in AIME. Subsequently, we move on to two examples from IPCC plenaries: a discussion on climate sensitivity and conflict pertaining to an 'infographic' on climate impacts. We follow up on these examples by discussing Latour's more recent work (Latour et al. 2011; Latour 2013) on political representation and propose ways to refurbish the IPCC plenaries as more inclusive platforms for political deliberation on climate governance. We conclude the paper by proposing ways in which Latour's ideas on diplomacy and political representation could be implemented more reflexively in the organization of the IPCC, instead of the non-reflexive way in which diplomacy has been done in the IPCC until now.

\section{Latourian politics and diplomacy}

Throughout his work, Latour abstains from the idea that scientific knowledge can be based on an objective and accurate representation 
of a presupposed outside world that is readily available to be known. For example, Latour $(1993,1999)$ argues that only the study of scientific practices can explain how scientists attribute objectivity, accuracy, reliability, and truth to scientific knowledge. The work and maintenance that make up scientific knowledge can be explained by an analysis of networks of human and non-human 'actants', and the ways in which these actants are brought together and change through a process that Latour describes as 'translation', which refers to "the work through which actors, modify, displace, and translate their various and contradictory interests" (Latour, 1999: 311). Translation produces actor networks that are hidden from view in a process identified as 'purification', which implies scientific theories are detached from their history, obtain the status of 'objective' representations of nature, and are granted the ability to speak on behalf of nature.

Thus, Latour (1993) studies scientific practices with the aim of supplanting epistemological assumptions pertaining to objectivity with the articulation of the multiple heterogeneous actants that make up actor networks. This analysis extends beyond scientific knowledge. Latour rejects the modernist dualism of mechanical nature versus society constructed ex nihilo, and argues there is no such thing as an a priori society. Modern conceptions of the world rely on strict bifurcations between Man, Nature, Mind, and Matter. As argued above in the introduction, Latour points to the existence of imbroglios of human and non-human actants that ultimately compose what we come to call 'society'. This rejection of a pre-given Society has repercussions for Latour's conceptualization of politics. Graham Harman (2014) argues that Latourian politics cannot be based on an idea of a state of nature, which obstructs the idea that a particular society or politics can correspond with or deviate from this state of nature. Society persists through translation and can neither be grounded "in natural right or in an unquestionable sovereign authority", nor can it be based on the idea of a "natural human equality or the irreducible character of diversity in a world devoid of absolute truth" (Harman, 2014: 30). Political truths are provisional and are composed of networks that are forged by the most powerful actants.
In his later work, Latour $(2011,2013)$ no longer wishes to reduce all actors to the same ontological footing, and instead emphasizes the distinctions between various 'modes' of being and emphasizes the plurality of worldviews that, taken together, compose the world we live in. Different domains (e.g. science, law, and economics) imply different ontologies, or (combinations of) 'modes of existence'. Drawing on terms from semiotics, Latour compares the notion of mode of existence with 'regimes of enunciation', which

\footnotetext{
set up what comes next without impinging in the least on what is actually said.

Like a musical score, the regime merely indicates the tonality, the key in which one must prepare to play the next part. So this is not about looking for what is underneath the statements, their condition of possibility, or their foundations, but a thing that is light but also decisive: their mode of existence. It tells us 'what to do next'. (Latour, 2011: 309.)
}

There is no knowing object or knowing subject a priori to a mode of existence. Rather than being pre-existing categories, modes of existence emerge from historically and culturally specific sites.

In a world populated by various modes of existence, metaphysicians are involved with diplomatic work across different modes, effectively furnishing intercultural work through which confused ontologies can be untangled and understanding between various social groups can be reached (Maniglier, 2014). AIME aligns well with the increasingly wide-spread realization that modernist facts and values, such as Mind and "the institution of matter" (Latour, 2013: 118), are running out of steam and need to be re-envisioned as values rather than objective facts, especially vis à vis present-day ecological crises. The process of untangling the Modern constitution is referred to as 'ecologizing modernity', which requires the constitution of a "whole new diplomacy" (Latour, 2013: 103) that is able to accommodate different modes of existence. Articulating modes of existence involves ontology, seen as an inquiry into the existence of things, as well as studying the relations these things entertain and the behaviors and values they exhibit. Seen in this way, ontology is ecology. 
Diplomacy is a necessary activity in the face of a plurality of modes of existence. Latour (2002) explains diplomacy as a way to furnish 'multinaturalism', where different values form a unity as "the end result of a diplomatic effort" (Latour, 2002: 3). Diplomats are invited to let go of grand modern categories like Science, whilst retaining the power of the sciences (Latour, 2002: 45) and letting negotiations between different perspectives "resume in earnest" (Latour, 2002: 48). This approach to diplomacy aligns well with Latour's work in AIME, which entails the following ideas about diplomacy:

\begin{abstract}
The present investigation is presented as a diplomatic enterprise in the sense that there is no outside arbiter - survival of the fittest, universal reason, state, law, laws of nature etc. In this case, for want of a "referee" acceptable to all, we must "retake language" and, with the aid of a minimal number of forms, organize identification and bring negotiable and non-negotiable positions into contact with each other. It is because the common world needs to be composed that we must have recourse to a diplomatic procedure. (Latour, 2014)
\end{abstract}

The introduction of AIME (Latour, 2013: 2-6) contains an anecdote of a scientist who takes recourse to an explanation that illustrates the diplomatic character of AIME. Latour alludes to a climate scientist who is criticized by a climate skeptic. Rather than taking recourse to science's potential to acquire objective and reliable knowledge, the climate scientist does not invoke a presupposed epistemic process of Science to defend his claims. Instead, he goes on to list the various means through which a scientific understanding of climate change is produced. Speaking in terms of Latour's own Actor Network Theory (ANT), the scientist in question maps out the various elements of the network in which he himself is enrolled. This imbroglio of objects, agencies, and institutions has the ability to manufacture 'objective' knowledge. Latour not only delights in the description of science thus given, but also thinks this is the right way forward for the climate scientist. Retaining the power of the sciences involves articulating the 'chains of translation' (Latour, 1999: 91ff.) that make up scientific knowledge. Constructivist analyses of the sciences reframe scientific practice and could lead to "opening the peace talks again by rephrasing the war aims of all parties" (Latour, 2002: 41).

Such a constructivist exposition of chains of translation in climate science is also important due to the plurality of voices that can be found in the author teams responsible for writing the IPCC reports. The IPCC bases its reports on substantial reviews of scientific publications and is not involved with doing research itself. Although the authors need to base their findings on scientific publications that discuss various aspects of climate change, they often end up having diverging interpretations. As a result, different perspectives on climate change need to be condensed into an 'objective' representation of the current state of climate science. For this reason, it is important that the IPCC acknowledges the role of expert judgment. Thus, the scientific underpinning of the IPCC's findings is made amenable for contestation if deemed necessary. A further example of this is the development and implementation of criteria to assess the quality of scientific findings by using 'uncertainty' qualifiers, which enhances the transparency of IPCC documents by exposing the chains of reference and the underlying scientific processes. Those involved acquire the possibility to understand how the scientific basis of the IPCC's findings was established.

Latour's proposal to expose the chains of translation of science does not mean that he thinks the values of the Moderns simply need to be abandoned. If 'we have never been modern', as Latour (1993) has stated, the question is to ask what we have been instead. AIME emerges as a positive version of Latour's earlier diagnosis of the Moderns. Rather than rejecting the values of the Moderns outright, the diplomatic task at hand here is to understand the experience and modes peculiar to the Moderns. The diplomat enables the Moderns to speak out for their own values in a way that fosters negotiation with other modes. It is the task of the diplomat to help the various parties in a conflict find out what it is they are fighting for (Latour, 2002: 50). The perspectives of all involved are approached in a'respectful' manner. Put differently, it is important not to reduce the perspective of one practitioner to that of another, e.g. by reducing one practice to another by arguing 
that science is only a social construction, or by reducing differences to an irreducible opposition, e.g. by radically opposing science with politics or religion.

Diplomacy involves identifying the different 'interpretive keys' (Latour, 2013: 319) that belong to different modes of existence and making sure that category mistakes are avoided: "the rational degenerates into parasitic rationalization as soon as we lose or confuse the keys" (Latour, 2013: 319). Diplomacy involves "a practical relationalism that seeks, in a protocol of relationship-building and benchmarking, to avoid the ravages of relativism - that absolutism of a single point of view" (Latour, 2013: 481). In other words, Latour's diplomacy is a plea for a pluriverse that accommodates a multiplicity of modes of existence. The figure of the diplomat, "as devious as he is naïve" (Latour, 2013: 484), plays an important role. Constructing a more accommodating pluriverse does not involve bringing down existing institutions, but rather the accommodation of different modes of existence: "[w]hat we want is an institution that follows the trajectory of its own mode of existence without prejudging the rest, without insulting the others" (Latour, 2013: 482).

As we show below, diplomacy helps to foster a more inclusive form of climate governance, e.g. by better accommodating the interests of all involved. We provide two examples of diplomacy in action. In each case, we outline the perspectives and actions of those involved, and perform a diplomatic analysis ourselves, i.e. by attempting to untangle confused modes of existence. In addition, we explain how diplomatic interventions along the lines proposed by Latour could inform the negotiations during IPCC plenaries. As a result, diplomacy could have helped to establish a more inclusive and reflexive space of negotiation in which the perspectives of those involved are accommodated, ensuring the possibility of seeking acceptable compromises.

\section{Diplomacy in action 1: climate sensitivity}

Our first example of diplomacy in action discusses events on the last day of plenary approval session for the Working Group I contribution to the IPCC's
Fifth Assessment Report (AR5) in Stockholm (Thursday 26 September 2013). Working Group I addresses natural science questions pertaining to the climate system: e.g. how much warming do the greenhouse gases that are emitted by human activity cause? The negotiations in this example of diplomacy in action concern the politically and scientifically sensitive issue of the 'equilibrium climate sensitivity', which is a theoretical quantity that represents how much the Earth would warm up in the long run from a doubling of the carbon dioxide concentration relative to the pre-industrial era. For many decades the estimates for this quantity have ranged between $1.5^{\circ} \mathrm{C}$ and $4.5^{\circ} \mathrm{C}$. Given that the world had already decided to keep the temperature below $2^{\circ} \mathrm{C}$, this theoretical quantity, an in particular its uncertainty, could be regarded as politically relevant in the climate negotiations: when the climate sensitivity is high the greenhouse gas emissions will have to be reduced further to keep the temperature below $2^{\circ} \mathrm{C}$ than when the sensitivity is low.

This issue was sensitive in Stockholm even more since it had already been in the news (through 'leaks') that the range of the 'climate sensitivity' compared to the previous IPCC report (AR4, 2007) was to be adjusted. Because of new studies, the lower bound had gone down to $1.5^{\circ} \mathrm{C}$, while it had temporarily (since 2007 ) sat at $2^{\circ} \mathrm{C}$. Politically, some countries wanted to highlight that climate may be less sensitive to greenhouse gas emissions, while other countries could not stomach the emphasis on the (lowered) low scenario - they wanted to retain emphasis on the (unchanged) high scenario. Scientifically, more references had become available based on a particular type of estimation methods (which gave lower climate sensitivity outcomes). Effectively, the narrative of the authors in the construction of the new climate sensitivity range had changed from the narrative of six years earlier. This is nothing to be embarrassed about: every round the evidence base has evolved and every round the authors are asked to give their best expert judgment.

In the plenary session the authors proposed to delete the following sentence from the summary:

The lower temperature limit of the assessed likely range is thus less than the $2^{\circ} \mathrm{C}$ in the AR4. 
The suggestion to omit this sentence was based on the argument that the ranges between the subsequent reports were incomparable due to differences in methodology. According to the authors, the way chains of reference were built up were different from one report to the next [REF]. Some countries objected: they claimed that policy-relevant information would then disappear from the summary and they could not accept that. For them, deletion of this sentence would make it more difficult to politically rally groups around the claim that climate change could be less severe than was expected earlier [POL], although they could not admit this so openly in the IPCC proceedings. Subsequently, after the plenary meeting could not reach an agreement, one of us (AP) found himself later that morning around a standing table in an informal consultation group on the climate sensitivity text. The representatives of a number of countries had been sent out of the session to negotiate with each other and with the authors. There were countries that found it important that a comparison was made with AR4 and there were countries against doing this. There was a mix of reasons and motivations, clearly at the crossing of the modes of reference [REF] and politics [POL], but also uncertainty guidelines [ORG] and emotional attachments [ATT] of both country delegates and authors were thrown into the mix (including AP's own, who had strong views on how uncertainties had to be addressed and was highly driven to obtain closure on this matter). These negotiations took place in a 'pressure cooker', since the chair of the session wanted to have results quickly.

The initial proponents of keeping the eliminated sentence found it very relevant for their policy-makers to show that the lower limit has been reduced - and stated so. Opponents used two arguments to defend the deletion: (1) by highlighting just the lowering of the lower bound one ignored that the upper bound had remained the same, and for many policy-makers the upper bound was at least as important as the lower bound; (2) the methodologies differed between AR4 and AR5, so that the range would be incomparable. Having heard all this, the authors together produced a new draft text, in which they went along with the opponents, picking up on their second argument. However, in this way they did not get their politics right. The authors were wrong to assume that that argument would sway the initial proponents of keeping the eliminated sentence (and AP thought, that the argument was not sound anyway).

AP saw all of this happen and concluded that they were not going to converge in this way. He realized that a compromise was possible along the line of the first argument of the opponents. For a moment, this compromise had been on the table as an acceptable option for important proponents and opponents: refer to both the reduction of the lower bound and the unchanged upper bound. This should be easy! But the authors had by now been put entirely on the wrong track, so he would have to make a very solid intervention, against the authors and against a powerful country. And he had to speak to the authors in terms of underpinning [REF] after he had spoken to the country most strongly pushing for the phrase on the lowering of the lower limit in terms of interests [POL]. So he asked the authors first to confirm that AR4 and AR5 ranges, although they have been established in different ways, are indeed similar in that they both represent an expert judgment with a similar degree of likelihood. They could not deny it, and reluctantly they confirmed it. Then he scored his goal: this meant that the argument that the ranges were not methodologically comparable was invalid, and that nothing stood in the way for the authors to include upper and lower bounds for both AR4 and AR5. He also mentioned that this compromise was already at hand and strongly urged the countries to now agree with it. This diplomatic intervention struck the right keys both scientifically and politically, effectively prevented a further dynamic and led to convergence within the next 5 minutes. They could all go back to the plenary hall, where the session was slowly but surely on the way to the finish line. A little later the following phrase came along: "The lower temperature limit of the assessed likely range is thus less than the $2^{\circ} \mathrm{C}$ in the AR4, but the upper limit is the same". No country had any further comments and the text was approved. 


\section{Diplomacy in action 2: representing climate impacts}

As illustrated above, the intended outcome of each plenary session of the IPCC is a policy-relevant document that addresses climate change in a topical manner, is adopted by all countries involved, and acts as an international benchmark for subsequent research on climate change and climate-related policymaking. In practice, this means that agreements are established through negotiations where diverging interests meet and agreements can be produced, often in the form of compromises. Here we give a second example of such a process of negotiation, this one featuring diverging perspectives on an information graphic, or 'infographic'. Even though these negotiations featured only partially compatible interests, the parties involved did eventually reach an agreement.
During the plenary session of the Synthesis Report, the figure below (Figure 1) was presented for consideration to the countries present. The figure locates observed impacts of climate change at geographical locations. The impacts in question can be attributed to climate change with varying levels of confidence (see the explanation of attribution in the lower-left corner). Attribution turned out to be the subject of much debate. Impacts that cannot be attributed to climate change in a 'scientifically acceptable' manner (i.e. being up to par with the scientific standards upheld by the IPCC) are not included in the figure [REF]. Several countries from Africa, Latin America and South America proposed to customize and even remove the figure, since they observed large gaps between the figure and 'reality': for them the impression conveyed by the figure was politically hard to swallow [POL]. One delegation remarked that the figure was also representative of differ-

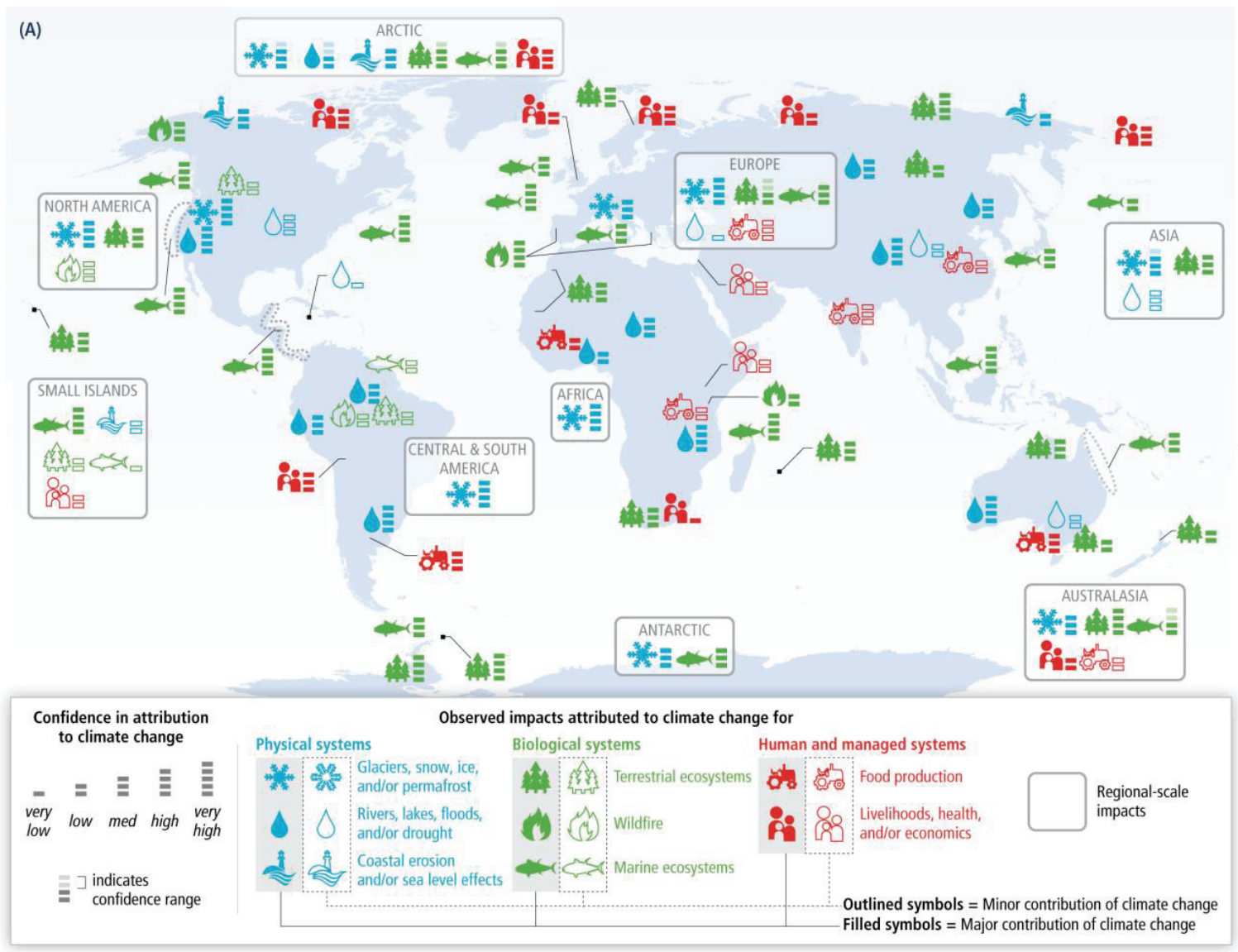

Figure 1. Figure SPM.2A (IPCC, 2014a: 7) showing observed impacts that can be attributed to climate change for physical, biological, human, and managed systems. As discussed in the text, this map was the subject of a heavy debate. 
ences in the availability of funds for scientific research: since developed countries had more resources to do research on the extent to which impacts can be attributed to climate change, this also led to a higher chance of successful attributions of impacts to climate change and a larger number of attributed impacts included on the figure. This should accordingly lead the IPCC to have moral scruples over this figure [MOR]: in the poor countries the impacts of climate change are expected to have more negative effects but they are at the same time less well known because they are less studied, which could be seen as a 'perversity' indeed.

These concerns, coming from other modes of existence, were understandable to many delegates (including MK), because the figure represented an extremely important aspect of climate governance, namely the extent to which climate change already had a negative impact. Although attribution was addressed in the caption of the figure, it was conceivable that a figure like this would take on a life of its own. As Latour (1986: 19) points out, "[t]here is nothing you can dominate as easily as a flat surface". It would probably be widely shared, and the subtleties behind 'attribution' might not be taken into account. Rather, the figure was likely to act as an exhaustive representation, which would also be due to the perceived authority of the IPCC.

But the authors were at first not open for a diplomatic exchange. They kept repeating that attribution of observed impacts had to be based on available scientific literature, which was evaluated on the basis of scientific criteria and guidance upheld by the IPCC, implying a 'crossing' of [REF] and [ORG], which Latour writes as [REF - ORG $]^{5}$. A crossing of modes joins modes that have different effects. In this case, representation on the basis of scientific criteria [REF] is combined with the IPCC's procedural requirements [ORG], yielding an obdurate mixture of knowledge deemed scientifically sound that also aligned correctly with the IPCC's procedural criteria. The authors of the figure stressed that their work had already been approved during the Working Group II session of the IPCC in Yokohama in March 2014 [LAW]. According to its authors, the figure constituted a "major advancement" and was repre- sentative of global impacts that could be reliably attributed to climate change. This information was meant to provide a scientific basis to advocate for adaptation and mitigation. In addition, the figure also provided insight into topics that needed to be studied more extensively, and the geographical areas where more work on the impact of climate change needed to be done. In other words, the figure had an illustrative role, but also an epistemic one as an articulation of knowledge gaps.

One delegation proposed to update the caption of the figure by adding a sentence stating that an impact missing on the map did not mean that this impact in question has nothing to do with climate change. After more negotiations, the following caption was proposed:

Figure SPM.4: Widespread impacts in a changing climate: Based on studies since the AR4, global patterns of impacts in recent decades attributed to climate change. Symbols indicate categories of attributed impacts, the relative contribution of climate change (major or minor) to the observed impact, and confidence in attribution. Locations without symbols may be affected by climate change impacts that have not yet been detected and attributed to climate change. See WGII SPM Table SPM.A1 for descriptions of the impacts.

Apparently, the authors had started to engage with the image in a diplomatic manner. Still, the aforementioned explanation and proposed caption did not appear to advance the discussion. One group of delegations emphasized the importance of displaying only impacts that could be legitimately attributed to climate change. Others stressed that the average policymaker would literally see the figure as a truthful representation of impacts of climate change. In short, one group emphasized the quality of the scientific process that led to the figure [REF], the other group reasoned from the perspective of policymakers and politicians and how they could mobilize groups using the figure [POL]. Once again, the authors retorted that there was political relevance of keeping the figure as it was: via the scientific process underlying the figure it had been possible to convey the fact that there are indeed global impacts that can be attributed to climate change [REF], and that climate change is no longer a hypotheti- 
Widespread impacts attributed to climate change based on the available scientific literature since the AR4

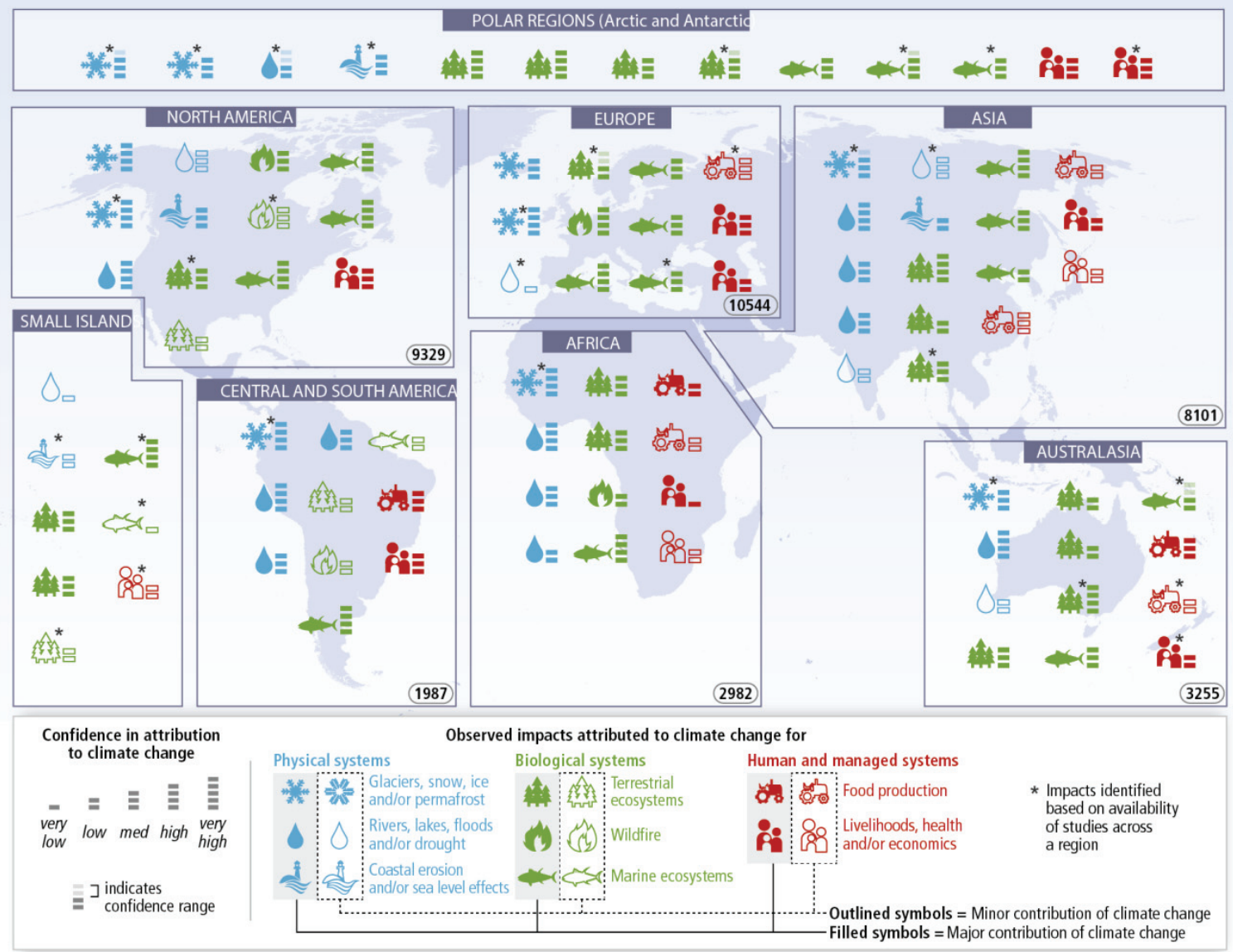

Figure 2. Figure SPM.4 (IPCC 2014b, 7) showing impacts that can be attributed to climate change according to scientific criteria established by the IPCC, as discussed during the finalization of the Synthesis Report.

cal problem and needs to be treated as a political issue [POL].

The day after the foregoing events transpired, an agreement was reached in the form of a new figure (Figure 2). Due to the political sensitivity of the figure and the resistance encountered by its authors, a different design was chosen as an alternative. The map no longer actually functioned as a map, but rather as a collection of icons that represented observed impacts, which were displayed in a box that had the continent in question as a backdrop. However, the actual location of the observed impacts was now no longer represented. The new design coupled observed impacts to entire continents, causing the observed impacts to lose geographical specificity. In other words, whereas the previous figure allowed the coupling of an observed impact to a specific region, the new figure was more like a collection of impacts. The graphical representation of the continents had become a background, and now only provided general information about the location of observed impacts. Thus, content present in the previous version of the figure - the explicit information about the geographic specificity of observed impacts - was now (literally) wiped off the map: in the new chain of reference some information that was included in the previous version was lost [REF]. That being said, the new figure included a hint on the moral issue identified the day before: the numbers at the bottom of the boxes of each continent indicated the number of references on which the attribution of observed impacts for that continent was based (itself a measure for how many studies had actually been done). This proposal constituted an acceptable compromise for the plenary, but it had not come easily from the side of the authors. 
MK with hindsight saw the proceedings around these figures as a lost opportunity. The density of information appear to be rather large and the boundaries of the paper format appear to have been reached. Although more and more voices within the IPCC had argued that different platforms and formats for dissemination needed to be explored, this was not the case during the foregoing negotiations. In the end, the question is whether the present form of the infographic suffices. The authors of the infographic were forced to implement a different design that no longer articulated the blind spots of research on climate impacts geographically on the map (although they did show up in the numbers in the lists). The interests of the various government representatives who contested the initial design had acquired a more 'balanced' representation of climate impacts, but one that lacked important geographical information: such information on attribution could have been mobilized in order to plea for additional research on climate impacts in specific geographical regions.

It appears that the clash between [POL] and [REF] here had created a compromise with potentially profound repercussions. Neither group had emerged victorious and there was relatively little understanding among the opposing country delegates for the intentions of the authors of the infographic. [POL] had impinged quite radically on the process of representing climate impacts.

\section{The political circle}

As became clear in the foregoing, delegations partaking in the IPCC plenaries attempt to have their interests met, which entails the consolidation of a multitude of voices due to the different and often incompatible agendas of the delegations and authors involved. Although diplomacy can be of benefit in terms of articulating values and building consensus between different delegations and with authors, it is not a silver bullet that will always yield a solution. Delegations may find their interests unaddressed and the authors of IPCC reports may find that their hard work on climate science is not taken up in the political process that is also involved in approving a report's summary. However, as we show in this section, Latourian diplomacy is a crucial building block for a more inclusive and accommodating and more reflexive - form of climate governance. To bring home this claim, we need to explore [POL] in more detail, the mode of existence with which many IPCC authors could engage more productively.

[POL] should not be confused with [REF], since this would feed into disillusionment in the form of a belief in 'rational politics'. This technocratic form of politics [POL - REF] leans heavily on positivistic science, and assumes scientists 'speak truth to power' by feeding scientific findings into the process of policymaking. The implication of rational politics is that scientific knowledge can simply be taken up as is, without any mediation. However, there is no such thing as knowledge or truth without mediation in a Latourian ontology: "[d]emanding that scientists tell the truth directly, with no laboratory, no instruments, no equipment, no processing of data, no writing of articles, no conferences or debates ... without stammering [or] babbling, would be senseless" (Latour, 2003: 147 quoted in Harman, 2014: 83). The IPCC's relationship with science, expressed in the often-encountered dictum "policy relevant but policy neutral", is unable to account for the processes of mediation that take place once scientific knowledge needs to be taken up by policymakers.

Like the other modes, [POL] has its own felicity conditions involving language and action that unifies internally conflicting and disparate 'multitudes', or masses of people. For Latour, [POL] entails a cycle from multitude to political representation that is never-ending and inherently disappointing: some voices are amplified whilst others are drowned out in the tumultuous uproar of the agora. Political representation involves the articulation of a position, but once this position is articulated and achieves political representation, other positions are excluded. The cycle from multitude to representation may lead to the dissolving of representation due to the concerns of a multitude that feels its concerns are insufficiently represented: "the ruler inevitably betrays the ruled and the ruled betrays the ruler in turn, through a series of translations or remixes of what one seems to tell the other" (Harman, 2014: 86). As a result, the cycle from multitude to representation will begin again, starting from a new and changed 
multitude that once again attempts to construct political representation. There is no way in which the concerns of a particular multitude can simply be fed into politics. Believing the contrary would ignore the necessity of mediation, much like the aforementioned belief in rational politics.

Taking very specific and fixed political motivations as a starting point in negotiations will most likely frustrate political deliberation: those who demand their interests are met 'as is' are effectively doomed to disappointment, since any compromise will be framed as betrayal. The development of political representation is profoundly vulnerable: the political circle "can at any moment grow larger by multiplying inclusions, or shrink by multiplying exclusions. Everything depends on its renewal, on the courage of those who, all along the chain, agree to behave in such a way that their behavior leads to the next part of the curve" (Latour, 2013: 342, original emphasis). The renewal of the political circle can establish a situation in which the renewal of the political circle is less painful or frustrating, though it might as well "take a turn for the worse" (Latour, 2013: 343).

In Latour's multiverse that is populated by adherents to various modes of existence, Nature is not so much a universally valid and unambiguous arbiter against which the value of other perspectives can be weighed, but rather a dividing figure. These insights can be extended to the IPCC plenaries, which rely on the natural, economic and social sciences, and the humanities, ${ }^{6}$ without those sciences having the power to unify the planet - they are not the ultimate epistemological arbiter that can settle conflicts once and for all, but modes among other modes. The IPCC may act as if there were such a final way to resolve conflicts between these modes, e.g. by heralding global climate models as impartial instruments that have the strongest voice in debates on climate change, but this ultimately entails a category mistake.

In those cases where [REF], or any other mode, is hailed as a superior mode that will function as a universally valid arbiter to settle debates is where diplomacy will prove most of its value, i.e. by ensuring that adherents of particular modes articulate why they subscribe to a particular idea, and subsequently trying as best as possible to accommodate these different perspectives in the final outcome of IPCC plenaries. As argued above,
[POL] is inherently disappointing, but is also 'experimental' in the sense that it refuses to settle on a particular way of doing politics: "[politics is] experimental because if we have to begin to agree on the basic furniture of the world ... then politics is certainly finished, because there is actually no way we will settle these questions" (Latour et al., 2011: 46). As our examples of diplomacy in action show, pluralism is a prominent part of IPCC plenaries. If the IPCC plenaries fail to accommodate this plurality of perspectives, the political circle is likely to frustrate, for example by establishing a strict form of rational politics in which [REF] is the mode of choice. Diplomacy would go a long way into making sure other modes are accommodated.

That being said, there are important ways in which diplomatic work can be supported by the institutional setting of the IPCC. Pleas to use different ways to frame the challenge of climate change have sounded both within and outside of the IPCC, where different authors question the ability of the IPCC reports to make an impact on policymaking. Tendentious reporting on climate science, for example during the 'Climategate' affair in 2009, during which e-mail communication of climate scientists working on IPCC reports became the subject of widespread criticism, in combination with more acute financial and geopolitical crises, obstructs the ability of scientists and policymakers to make climate change a matter of more general concern (Pielke, 2005; Marquart-Pyatt et al., 2011). There are also calls for institutional renewal within the IPCC. It has been pleaded for instance by AP, also in a session with delegates, that reforms are needed in order to improve the way data and findings are used by actors at national and subnational levels. This can be done through continuous assessment and monitoring of what needs to be done when and where, alternative reporting mechanisms and novel forms of output, producing more special reports in collaboration with other organizations, engaging user communities in the production of climate assessments, and sharing resources to enhance the participation of developing countries (Petersen et al., 2015). Organizational reform could lead to the IPCC becoming more inclusive and better adapted to the requirements of particular contexts. More attention could be paid to cross-cutting and more 
local issues, which could lead to the involvement of transnational organizations, multinationals, NGOs representing other non-national issues, and scientific organizations cutting through borders. Thus, one could argue, IPCC plenaries would shift from serving the self-interest of individual states to a different territorial attachment, effectively enacting new geopolitical frames of climate change. But it remains to be seen how far diplomacy can go to make this a reality.

\section{Conclusion: invoking the political circle, again and again}

What to make of the role of the diplomat after all of this? Latour (2004) draws inspiration from the work of Carl Schmitt, for whom the condition of war is defined by the absence of an indisputable arbiter who would be able to settle the conflict once and for all. In this context, the diplomat never uses "the notion of a common world of reference, since it is to construct that common world that he confronts all the dangers ... [h]e swallows his pride" (Latour, 2004: 212-213). Diplomacy may be experienced as a form of betrayal, as it involves the "[s]kill that makes it possible to get off a war footing by pursuing the experiment of the collective concerning the common world by modifying its essential requirements" (Latour, 2004: 240, emphasis added). In other words, the diplomat attempts to create new collectives by asking what can be given up in order to create such new collectives.

It is the work of the diplomat that can both enrich and frustrate the political circle. Diplomacy is a two-sided phenomenon: the betrayal that accompanies diplomatic intervention could lead to the exclusion of modes of existence, but may also lead to a renewed iteration of the political circle by taking up the challenge of articulating new collectives. Since so much hinges on the diplomat, a reasonable question is where he or she will come from, and what institutional setting will provide space to diplomatic interventions. Our suggestions concerning the latter matter provided in the previous section are only a modest beginning for such considerations. Let us end on a more positive note: the IPCC provides a fertile institutional setting for the exploration of such questions.
Diplomatic interventions have the potential to yield a more versatile and accommodating organization of the IPCC and its plenaries. Invoking the political circle again and again is a daunting prospect in terms of organizing, administrating, and maintaining the flexible political infrastructure that a more experimental Latourian politics entails. However, a more versatile and accommodating IPCC will help to address environmental challenges. It is not always possible for [REF] to be the preferred mode to settle debates in climate governance once and for all, which our case studies illustrate. Diplomatic intervention will position [REF] as a mode among modes, and will thereby inform the tremendous challenge of addressing climate change on a scale that truly encompasses global interests.

It is our expectation that Latour's diplomatic project can inspire the intermodal work described above. Thus, an inclusive space for environmental governance can be furnished without the presupposition of forms of politics that reach consensus. Rather, a more productive stance is to see politics as an interplay of forces, which may yield results that may very well be to the chagrin of those involved and society more generally. Latour's diplomatic project stresses the importance of taking up the struggle for political representation again and again, whilst acknowledging the struggle that this will entail. Even then, diplomats cannot provide an easy fix. As Latour himself admits: "As always, the parties in the conflict do not know exactly what they are fighting for. The task of the diplomats is to help them find out. And, of course, their offer of mediation, like mine, may fail" (Latour, 2002: 50-51). If anything, diplomats can enhance reflexivity about the modes at play in climate governance, and thereby help to build a more broadly shared acknowledgment of environmental governance as a problem strongly related to pluralism.

\section{Acknowledgements}

The authors wish to thank participants of the UCL STEaPP workshop on "Bruno Latour and Environmental Governance" and two anonymous reviewers for their helpful comments on earlier versions of this paper. 


\section{References}

Bryant L, Srnicek N and Harman G (2011) Towards a Speculative Philosophy. In: Bryant L, Srnicek N and Harman G (eds) The Speculative Turn: Continental Materialism and Realism. Prahran: re.press, pp. 1-18.

Harman G (2014). Bruno Latour. Reassembling the Political. London: Pluto Press.

IPCC (2014a) Summary for Policymakers. In: Field CB, Barros VR, Dokken DJ, et al. (eds) Climate Change 2014 : Impacts, Adaptation, and Vulnerability. Part A: Global and Sectoral Aspects. Contribution of Working Group II to the Fifth Assessment Report of the Intergovernmental Panel on Climate Change. Cambridge \& New York, NY: Cambridge University Press, pp. 1-32.

IPCC (2014b) Summary for Policymakers. In: Pachauri RK and Meyer LA (eds) Climate Change 2014: Synthesis Report. Contribution of Working Groups I, II and III to the Fifth Assessment Report of the Intergovernmental Panel on Climate Change. Geneva: IPCC, pp. 2-31.

Latour B (1986) Visualization and Cognition: Thinking with Eyes and Hands. Knowledge and Society: Studies in the Sociology of Culture Past and Present 6: 1-40.

Latour B (1993) We Have Never Been Modern (trans. C Porter). Cambridge, MA: Harvard University Press.

Latour B (1999) Pandora's Hope: Essays on the Reality of Science Studies. Cambridge, MA: Harvard University Press.

Latour B (2002) War of the Worlds: What about Peace? (trans. C Bigg). Chicago, IL: Prickly Paradigm Press.

Latour B (2003) What if we talked politics a little? Contemporary Political Theory 2(2): 143-164.

Latour B (2004) Politics of nature: how to bring the sciences into democracy (trans. C Porter). Cambridge, MA: Harvard University Press.

Latour B (2011) Reflections on Etienne Souriau's Les différents modes d'existence. In: Bryant L, Srnicek N and Harman G (eds) The Speculative Turn: Continental Materialism and Realism. Prahran: re.press, pp. 304-333.

Latour B (2013) An Inquiry into Modes of Existence: An Anthropology of the Moderns. Translated by Catherine Porter. Cambridge, MA: Harvard University Press.

Latour B (2014) Diplomacy. Available at: http://modesofexistence.org/aime/voc/109 (accessed 1.3.2017).

Latour B, Harman G and Erdélyi P (2011) The Prince and the Wolf: Latour and Harman at the LSE. Winchester: Zero Books.

Maniglier P (2014) A metaphysical turn? Bruno Latour's An Inquiry into Modes of Existence. Radical Philosophy 187:37-44.

Marquart-Pyatt ST, Shwom RL, Dietz T, et al. (2011) Understanding Public Opinion on Climate Change: A Call for Research. Environment: Science and Policy for Sustainable Development 53(4): 38-42.

Meyer L and Petersen A (eds) (2010) Assessing an IPCC Assessment: An Analysis of Statements on Projected Regional Impacts in the 2007 Report. PBL Report 500216002. The Hague and Bilthoven: PBL Netherlands Environmental Assessment Agency.

Petersen A, Blackstock J and Morisetti N (2015) New leadership for a user-friendly IPCC. Nature Climate Change 5(October 2015): 909-911.

Pielke RA (2005) Misdefining "climate change": consequences for science and action. Environmental Science \& Policy 8: 548-561. 


\section{Notes}

1 'Science' is understood broadly here and encompasses not only the natural sciences, but also engineering, economics, social sciences, and the humanities.

2 In Latourian (2013) terms (see below) one could say that these co-chairs embody a 'crossing' of the mode of reference [REF] and the mode of politics [POL]. They have to speak well in both modes and are always at risk of being understood in the wrong key.

3 All modes used in this paper are based on Latour (2013).

4 While in practice specialists typically do not receive any comments from high-level civil servants or ministers on the governmental instruction, one way political awareness did trickle through in the Dutch instructions for the Fifth Assessment cycle was their emphasis on requiring sufficient underpinning of summary conclusions in the underlying report, in order to prevent political criticism on the IPCC's quality assurance procedures. Thus, for political reasons [POL], the way summary conclusions reference underlying text [REF] had becomes even more salient. See also Meyer and Petersen (2010).

5 Crossings discussed below follow the same formatting.

6 The IPCC takes all these sciences together under the mode of reference [REF]. Note that Latour (2013) does not categorize economics under this mode, nor would he categorize humanities subjects such as ethics under it. 